\title{
Skin basement membrane and extracellular matrix proteins characterization and quantification by real time RT-PCR
}

\author{
Tzu-Wei Wang ${ }^{\mathrm{a}}$, Jui-Sheng Sun ${ }^{\mathrm{b}, \mathrm{c}}$, Yi-Chau Huang ${ }^{\mathrm{a}}$, Hsi-Chin $\mathrm{Wu}^{\mathrm{a}}$, \\ Li-Tin Chen ${ }^{d}$, Feng-Huei Lin ${ }^{\mathrm{a}, *}$ \\ ${ }^{a}$ Institute of Biomedical Engineering, College of Medicine and College of Engineering, National Taiwan University, \#1, Sec. 1, Jen-Ai Road, \\ Taipei 100, Taiwan \\ ${ }^{\mathrm{b}}$ Institute of Rehabilitation Science and Technology, National Yang-Ming University, Taipei, Taiwan \\ ${ }^{\mathrm{c}}$ Department of Orthopedic Surgery, Taipei City Hospital- Yang-Ming Branch, Taipei, Taiwan \\ ${ }^{\mathrm{d}}$ Department of Research and Development, Healthbanks Biotechnology Corporation Ltd, Taipei, Taiwan
}

Received 22 March 2006; accepted 10 May 2006

Available online 15 June 2006

\begin{abstract}
Three-dimensional gelatin-chondroitin 6 sulphate-hyanuronic acid (gelatin-C6S-HA) biomatrices were used as the scaffold to investigate the phenotypic and molecular expression of basement membrane (BM) and extracellular matrix (ECM) proteins in vitro. The cells were cultured in three different culture conditions: keratinocytes (K) monoculture, or dermal fibroblasts (FB) monoculture, or organotypic keratinocytes and dermal fibroblasts $(\mathrm{K} \& \mathrm{FB})$ coculture model. The deposition of BM proteins and ECM proteins secreted by these two kinds of cells was quantitatively characterized by real time RT-PCR and examined by immunohistochemistry.

The results showed that $\mathrm{K}$ expressed specific keratin and E-cadherin proteins, while type I collagen was secreted by FB. FB were shown to synthesize and deposit laminin 5, type IV collagen, and type VII collagen, whereas K dominantly produced integrin alpha 6 and integrin beta 4 as well as laminin 5. Interestingly, the integrin beta 4 was expressed neither in K monoculture nor in FB monoculture, but was seen in organotypic K\&FB coculture model in the early culture stage.

The histology studies revealed numerous features of epidermalization including a well organized basal layer of distinct cylindrical cells, granular and a horny layer, as well as complete BM formation. These results indicated that K and FB not only kept their phenotype when culturing on 3D scaffold, but also worked together to reconstruct dermal-epidermal basement membrane zone. In brief, our results directly provide the quantification in the expression of BM and ECM proteins by using real time RT-PCR in mRNA level and morphological appearance by immunostain in protein level.
\end{abstract}

(C) 2006 Elsevier Ltd. All rights reserved.

Keywords: Keratinocyte; Fibroblast; PCR (polymerase chain reaction); Biomimetic material

\section{Introduction}

The basement membrane (BM) is a specialized structure separating the epidermis from the underlying dermis. It also plays important roles in adhesion between epidermis and dermis and in controlling epidermal differentiation [1].

\footnotetext{
Abbreviations: BM, Basement membrane; ECM, Extracellular matrix K, Keratinocytes; FB, Dermal fibroblasts; K\&FB, Keratinocytes and dermal fibroblasts; RT-PCR, Reverse transcription-polymerase chain reaction

*Corresponding author. Tel.: + 886223912641 ; fax: + 886223940049.

E-mail address: double@ha.mc.ntu.edu.tw (F.-H. Lin).
}

It is likely that the presence of BM on artificial skin may contribute to the resilience and attachment of the epidermal component [2]. The BM at the dermal-epidermal junction is known to be composed mainly of laminins, integrins, type IV collagen, type VII collagen, nidogen, and perlecan, etc. $[3,4]$.

The skin diseases that result from disruption of the structures in the dermal-epidermal junction present clinically with skin fragility and blistering. The prototype of these diseases is epidermolysis bullosa, a group of heritable disorders characterized by blistering of the skin and mucous membranes [5]. The previous studies have shown 
that laminin 5 was essential to epidermal attachment, as mutations in the genes of laminin 5 chains underlie the severe blistering phenotype of Herlitz' junctional epidermolysis bullosa [6]. Type VII collagen was initially identified as the target antigen of bullous systemic lupus erythematosus, which is a generalized subepidermal blistering skin eruption in patients suffering from systemic lupus erythematosus [7]. Inherited mutations in keratins cause epidermolytic hyperkeratosis (EHK). A defect in EHK weakens the structural stability of the keratinocytes (K), causing easy blistering, hyperproliferation, and hyperkeratosis [8,9]. People, who make antibodies against a particular epidermal cadherin, produce a life-threatening disease called pemphigus vulgaris, wherein the epidermal cells lose their cell-cell adhesion, blister, and fall off the body [10,11]. Quantification and immunostaining of skin using an adequate panel of antibodies may detect the abnormal expression of a specific $\mathrm{BM}$ component and identify the candidate genes in these diseases $[12,13]$. It is also suggested that low or abnormal expression level of these $\mathrm{BM}$ and extracellular matrix (ECM) proteins induces assembly of immature hemidesmosomes and fails to assure a stable cohesion of the dermal-epidermal junction [14]. With such devastating effect to human life, it is important and valuable to investigate and clarify fundamental biological questions about the mechanisms of these skin genetic diseases in relations to skin basement membrane and extracellular matrix proteins.

Detailed information on the mechanisms controlling the BM formation is difficult to obtain by in vivo studies. However, the in vivo situation can be closely approached with organotypic skin equivalent culture model $[15,16]$. In this study, we used our previously designed three-dimensional gelatin-chondroitin 6 sulphate-hyanuronic acid (gelatin-C6S-HA) biomimetic scaffold to investigate the phenotypic and molecular protein expression of human $\mathrm{K}$ and dermal fibroblasts (FB) in three different culture conditions in vitro [17-19]. Chondroitin-6-sulfate (C6S) and hyaluronic acid (HA) were incorporated within the gelatin membrane to mimic skin extracellular matrix composition and to create an appropriate microenvironment for cell growth [20,21]. The bi-layer skin equivalent was originally designed and fabricated with two different pore sizes. The pore size in the lower layer about $75-150 \mu \mathrm{m}$ frozen at $-80^{\circ} \mathrm{C}$ is considered to be suitable for $\mathrm{FB}$ proliferation and migration. The pore size in the upper layer about $20-50 \mu \mathrm{m}$ frozen at $-196{ }^{\circ} \mathrm{C}$ is designed for $\mathrm{K}$ attachment and prevented $\mathrm{K}$ from falling into the lower layer. The cells were then cultured in either monolayer ( $\mathrm{K}$ or $\mathrm{FB}$ only) or organotypic coculture (K\&FB) model. The deposition of ECM and BM proteins secreted by these two kinds of cells was quantitatively characterized by real-time RT-PCR and examined by immunohistochemistry. In the previous studies, the exact amount of $\mathrm{BM}$ proteins at the dermal-epidermal junction and ECM proteins secretion by $\mathrm{K}$ and FB had not been investigated in detail $[2,15,16]$. In this study, we directly quantify the expression of BM and ECM proteins comprehensively and try to elucidate their complex synchronized interactions.

\section{Materials and methods}

\subsection{Preparation of porous bi-layered gelatin-C6S-HA membrane}

Gelatin, C6S, HA, and 1-ethyl-3 (3-dimethyl aminopropryl) carbodiimide (EDC) were all purchased from Sigma Chemical.

Gelatin solution ( $5 \mathrm{wt} \%$ ) was prepared by adding $5 \mathrm{~g}$ of gelatin powder (Cat. No. G-2500) dissolved in $100 \mathrm{ml}$ distilled water at $25^{\circ} \mathrm{C}$. C6S and HA were slowly added into the gelatin solution to a final concentration of 0.05 and $0.2 \mathrm{wt} \%$, respectively. The slurry solution was then well mixed at $30^{\circ} \mathrm{C}$ by magnetic stirrer for $1 \mathrm{~h}$. The well-mixed slurry $(0.5 \mathrm{ml})$ was poured into a preformed polyethylene mold, which was $3 \mathrm{~cm}$ in diameter and $1 \mathrm{~cm}$ in length. The slurry solution in polyethylene mold, frozen at the temperature of $-196^{\circ} \mathrm{C}$ for $30 \mathrm{~s}$, would form a porous membrane with pore size of $30 \mu \mathrm{m}$ in average. The porous membrane was then added another $0.5 \mathrm{ml}$ of slurry solution on the top and frozen at $-80^{\circ} \mathrm{C}$ for $3 \mathrm{~h}$ followed by lyophilizing at $-70^{\circ} \mathrm{C}$ overnight. Through this process, the bilayered porous membrane with upper layer in smaller pore size of $30 \mu \mathrm{m}$ in average and lower layer in larger pore size with $150 \mu \mathrm{m}$ in average would be prepared. The fabricated bi-layered membrane was cross-linked by $0.5 \mathrm{wt} \%$ EDC solution with $0.25 \mathrm{wt} \% N$-Hydroxysuccinimide (Cat. No. 56480 , Sigma) addition overnight at $4{ }^{\circ} \mathrm{C}$. The cross-linked membrane was finally immersed in disodium phosphate (Cat. No. S-7909, Sigma) solution, sonicated 5 times in distilled water for $10 \mathrm{~min}$ to remove residual EDC, and then froze at $-80^{\circ} \mathrm{C}$ for $3 \mathrm{~h}$ followed by lyophilizing at $-70^{\circ} \mathrm{C}$.

\subsection{Culture of keratinocytes and dermal fibroblasts}

Fresh human foreskin was obtained from human circumcision surgery with informed consent of the donors. The biopsies were washed by phosphate buffered saline with $5 \mu \mathrm{g} / \mathrm{ml}$ gentamycin (Cat. No. 15710 , Gibco Invitrogen Co., Canada). Specimens were then chopped into small fragments. The fragments were immersed in $40 \mathrm{U} / \mathrm{ml}$ thermolysin (Cat. No. T-7902, Sigma) at $4{ }^{\circ} \mathrm{C}$ overnight. For isolation of $\mathrm{K}$, the epidermis was separated from the dermis with forceps and then incubated in trypsinEDTA (Cat. No. 25300, Gibco, Invitrogen Co.) for $10 \mathrm{~min}$ at $37^{\circ} \mathrm{C}$. The isolated $\mathrm{K}$ were cultivated and expanded by commercially available K-serum free medium (SFM) with indicated medium supplement (Cat. No. 17005, Gibco Invitrogen Co.) in a 9-cm Petri dish. The dermis was treated with $0.2 \%$ collagenase (C-0130, Sigma) at $37^{\circ} \mathrm{C}$ for $2 \mathrm{~h}$ to harvest FB. The harvested FB were cultured in Dulbecco's Modified Eagle's Medium (DMEM) (Cat. No. SH30022.02, HyClone, UT, USA) supplemented with 10\% FBS (Cat. No. 12003-500 M, JRH Bioscience, KS, USA) at $37^{\circ} \mathrm{C}, 5 \%$ $\mathrm{CO}_{2}$. The 2 nd and the $3 \mathrm{rd}$ passages were used for the experiments.

\subsection{Reconstruction of skin equivalents}

The experiments were classified into three models that were briefly schemed in Fig. 1.

Model 1. Dermal fibroblasts (FB) monoculture: Fibroblast-seeded gelatin-C6S-HA membrane was prepared as follows. FB at a concentration of $5 \times 10^{5}$ cells $/ \mathrm{cm}^{2}$ were inoculated in the lower part (larger pore size) of the membrane. The dermal equivalent was immersed in DMEM supplement with $10 \%$ FBS for 2 days, and then plated to a 12-mm PTFE membrane $(0.4 \mu \mathrm{m}$ Millicell-CM insert; Millipore, Bedford, MA) mounted on the 48-well culture plate. The cells were cultured in a combination medium that was prepared by mixing DMEM supplement with $10 \%$ FBS and K-SFM in a volume ratio of 1:1. The cells were cultured for 7, 14, and 21 days (Fig. 1a).

Model 2. Keratinocytes $(K)$ monoculture: The epidermal $\mathrm{K}$ were seeded at a density of $5 \times 10^{5}$ cells $/ \mathrm{cm}^{2}$ on the upper layer of the gelatin-C6S-HA 

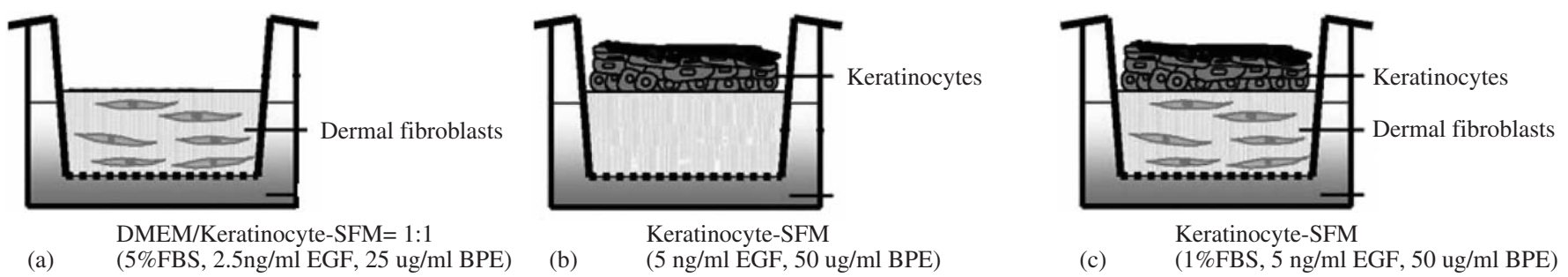

Fig. 1. The 3D culture models of skin equivalents and their culture medium. (a) model 1: dermal fibroblasts (FB) monoculture. (b) model 2: keratinocyte (K) monoculture. (c) model 3: organotypic keratinocytes and dermal fibroblasts (K\&FB) coculture. (DMEM: Dulbecco's Modified Eagle's Medium, Keratinocyte-SFM: Keratinocyte-serum free medium, FBS: Fetal bovine serum, EGF: Epithelial growth factor, BPE: Bovine pituitary extract.)

membrane, and then was plated into a 12-mm PTFE membrane culture insert in a submerged state for 2 days followed by at the air-liquid interface for up to 7, 14, and 21 days (Fig. 1b).

Model 3. Organotypic keratinocytes and dermal fibroblasts (K\&FB) coculture: The $\mathrm{K}$ were cultured on top of fibroblast-seeded gelatin-C6SHA membrane. The skin equivalents were lifted to air-liquid interface after 2 days in submerged condition. The cultures were maintained with growth medium consisting of DMEM and K-SFM in a volume ratio of $1: 1$, followed by culture in K-SFM supplemented with $1 \% \mathrm{FBS}, 5 \mathrm{ng} / \mathrm{ml}$ epithelial growth factor, and $50 \mu \mathrm{g} / \mathrm{ml}$ bovine pituitary extract (Fig. 1c).

\subsection{Total RNA extraction}

Total RNA was isolated from homogenized tissue samples in $1 \mathrm{ml}$ of TRIzol Reagent (Cat. No. 15596-026, Gibco Invitrogen Co.). In order to remove excessive proteins, an additional step has been adapted to include a $2 \mathrm{wt} \%$ of proteinase K (Cat. No. 19131, Qiagen, Hilden, Germany) digestion. The homogenate was incubated at $55^{\circ} \mathrm{C}$ for $10 \mathrm{~min}$ followed by centrifuging for $10 \mathrm{~min}$ at $12,000 \mathrm{~g}$ at $4{ }^{\circ} \mathrm{C}$. The resulting pellet contains extracellular membranes, polysaccharides, and high molecular weight DNA, while the supernatant contains RNA. In each case, the cleared homogenate solution was transferred to a fresh tube and chloroform and phase separation were proceeded with. Chloroform $(0.2 \mathrm{ml})$ (C-2432, Sigma) per $1 \mathrm{ml}$ of TRIzol was added. The tubes were shaken vigorously for $15 \mathrm{~s}$ and incubated at RT for $3 \mathrm{~min}$ followed by centrifuging at $12,000 \mathrm{~g}$ for $15 \mathrm{~min}$ at $4{ }^{\circ} \mathrm{C}$. RNA remained exclusively in the colorless upper aqueous phase. After transferring the aqueous phase to a fresh tube, $0.5 \mathrm{ml}$ of isopropyl alcohol per $1 \mathrm{ml}$ of TRIzol was added to precipitate RNA. The samples were incubated at RT for 10 min followed by centrifuging at $12,000 \mathrm{~g}$ for $10 \mathrm{~min}$ at $4{ }^{\circ} \mathrm{C}$. The RNA pellet was washed with $75 \%$ ethanol and centrifuged at $7500 \mathrm{~g}$ for $5 \mathrm{~min}$ at $4{ }^{\circ} \mathrm{C}$. RNA was dissolved in RNasefree water for RNA quality determination by UV spectrophotometer at the ratio of $260 / 280$.

\subsection{Quantitative reverse transcription $-P C R$}

pcDNA synthesis was performed on $100 \mathrm{ng}$ total RNA after treatment with GeneAmp ${ }^{\circledR}$ Gold RNA PCR Core Kit (Applied Biosystems, CA, USA.) including MultiScribe ${ }^{\mathrm{TM}}$ Reverse Transcriptase, 5X RT-PCR Buffer, RNase Inhibitor, $100 \mathrm{~mm}$ DTT, $10 \mathrm{~mm}$ dNTP Blend, $25 \mathrm{~mm}$ $\mathrm{MgCl}_{2}$, Oligo d(T) $)_{16}$.

Quantitative real-time PCR for human skin basement membrane and ECM proteins was performed using ABI PRISM ${ }^{\circledR} 7000$ Sequence Detection System (Applied Biosystems, CA, USA). A $7.5 \mu$ aliquot of the oligo dT-primed cDNA reaction were co-amplified by PCR in a $25 \mu \mathrm{l}$ reaction mixture containing $5 \mu \mathrm{l}$ of $3 \mu \mathrm{M}$ of primers, $12.5 \mu$ l SYBR ${ }^{\circledR}$ Green PCR Master Mix (SYBR Green 1 Dye, AmpliTaq Gold ${ }^{\circledR}$ DNA Polymerase, dNTPs with dUTP, Passive Reference 1, and buffer components). The primers used for amplifying were listed in Table 1. PCR was performed using the thermal cycle protocol listed as follows. Stage 1: $50^{\circ} \mathrm{C}$ for $2 \mathrm{~min}$; Stage 2: $95^{\circ} \mathrm{C}$ for $10 \mathrm{~min}$; Stage 3: 35 repetitions of $95^{\circ} \mathrm{C}$ for $15 \mathrm{~s}, 60^{\circ} \mathrm{C}$ for $1 \mathrm{~min}$. PCR products were separated by electrophoresis on a $2 \%$ agarose gel.

\subsection{Immunohistochemistry}

Specimens of organotypic K\&FB coculture model cultured for 3 weeks were fixed in $4 \%$ paraformaldehyde, dehydrated and embedded in paraffin. After deparaffinization, sections at $6 \mu \mathrm{m}$ thick were used for immunohistochemical analysis of laminin, type IV collagen, type VII collagen, integrin alpha 6 , integrin beta 4 , keratin, E-cadherin, and type I collagen. The primary antibodies used in this study were listed in Table 2. Samples were processed with heat epitope retrieval method in citrate buffer (Cat. No. 00-5000, Zymed Lab., CA, USA) to retrieve immunoreactivity. After incubation with primary antibodies, sections were stained with Super Sensitive Non-Biotin HRP Detection System (BioGenex, CA, USA). All sections were counterstained with hematoxylin.

\subsection{Statistical analysis}

All data were expressed as mean standard deviation and were analyzed by analysis of variance (One-way ANOVA) and Gauss' Law of error. Statistical significance was determined by Bonferroni's $t$-test. Probability values less than 0.05 were considered significant.

\section{Results}

\subsection{Expression of BM and ECM proteins}

Genes thought to have stable expression have been employed as controls in gene expression assays. Beta-actin has been used as house keeping gene for internal control.

In $\mathrm{K}$ monoculture at the 1st week, the threshold cycle $\left(C_{\mathrm{T}}\right)$ value was detected in $33.42,33.27$, and 31.7 for type IV collagen, type VII collagen, and integrin alpha 6 , respectively (Table 3a). Laminin 5 and integrin beta 4 were not detected at this culture time. It is suggested that BM reconstruction and adhesion on $\mathrm{K}$ in initial culture period were more dependent on type IV collagen, type VII collagen, and integrin alpha 6 rather than laminin 5 and integrin beta 4 . However, the $C_{\mathrm{T}}$ value of laminin 5 and integrin beta 4 was recorded when cultured for 2 weeks as well as for 3 weeks.

In FB monoculture at the 1st week, not only type IV collagen, type VII collagen, and integrin alpha 6 but also laminin 5 was expressed. The $C_{\mathrm{T}}$ values of type IV collagen, type VII collagen, integrin alpha 6 , and laminin 5 were $22.88,20.5,27.87$, and 29.02 , respectively. It seems that FB could secrete the above proteins to help K reconstruct BM at the initial culture stage. After culturing for 2 weeks, the investigated BM proteins were all appeared and constantly expressed even cultured for 3 weeks. 
Table 1

Real time RT-PCR primer sequence of target genes designed by the software of Applied Bioscience Prism 7000 sequence detection system

\begin{tabular}{|c|c|c|c|}
\hline Target Gene $(\mathrm{H})$ & $5^{\prime} \rightarrow 3^{\prime}$ & Primer sequence & Nucleotide position \\
\hline Beta-actin & Sense & GGACTTCGAGCAAGAGATGG & $704-937$ \\
\hline BC_002409 & Antisense & AGCACTGTGTTGGCGTACAG & \\
\hline Laminin 5 & Sense & TGACCTTTTCTGGCTCGTCT & $2842-3043$ \\
\hline NM_005560 & Antisense & GTTCAGCACAAAGGGCTCTC & \\
\hline Type IV collagen & Sense & GGATCGGCTACTCTTTTGTGATG & $4817-4969$ \\
\hline NM_001845 & Antisense & AAGCGTTTGCGTAGTAATTGCA & \\
\hline Type VII collagen & Sense & CGGAACTGACCATCCAGAAT & $1090-1294$ \\
\hline NM_000094 & Antisense & AATAGGGTGCTCACGGTCAC & \\
\hline Integrin, alpha 6 & Sense & TGCTGTTGGTTCCСТCTCAGAT & $1496-1601$ \\
\hline NM_000210 & Antisense & CTGGCGGAGGTCAATTCTGT & \\
\hline Integrin, beta 4 & Sense & GCCGCTACGAGGGTCAGTT & $1773-1963$ \\
\hline NM_000213 & Antisense & TCCATTACAGATGCCCCCATT & \\
\hline Keratin 10 & Sense & CATGAGTGTCCCCCGGTATC & $702-781$ \\
\hline NM_000421 & Antisense & CAGTATCAGCCGCTTTCAGA & \\
\hline E-cadherin & Sense & CATGAGTGTCCCCCGGTATC & $2497-2585$ \\
\hline NM_004360 & Antisense & CAGTATCAGCCGCTTTCAGA & \\
\hline Type I collagen & Sense & CCAGAAGAACTGGTACATCA & $4043-4138$ \\
\hline NM_000088 & Antisense & CCGCCATACTCGAACTGGAA & \\
\hline
\end{tabular}

Table 2

Lists of primary antibodies and their specificity used in immunohistochemistry

\begin{tabular}{|c|c|c|c|}
\hline Antigen & Antibody specificity & Dilution & Source \\
\hline Laminin & Monoclonal (human, pig, cat) & $1: 1000$ & Sigma, USA \\
\hline Type IV collagen & Monoclonal (human, monkey) & $1: 500$ & Sigma, USA \\
\hline Type VII collagen & Monoclonal (human, pig, bovine, sheep, goat) & $1: 1000$ & Sigma, USA \\
\hline Integrin, alpha 6 & Monoclonal (human) & $1: 1000$ & Abcam, UK \\
\hline Integrin, beta 4 & Monoclonal (human) & $1: 1000$ & Abcam, UK \\
\hline Keratin & Monoclonal (human, bovine) & $1: 200$ & Sigma, USA \\
\hline E-cadherin & Polyclonal (human) & $1: 30$ & Abcam, UK \\
\hline Type I collagen & Monoclonal (human, rat, rabbit, pig, cow, deer) & $1: 2000$ & Abcam, UK \\
\hline
\end{tabular}

At the 1 st week as shown in Table 3 a, integrin beta 4 was only expressed in the condition of organotypic K\&FB coculture model instead of in the $\mathrm{K}$ monoculture model and in FB monoculture model. The organotypic K\&FB coculture model was better than the other two monoculture models in BM proteins expression that was thought importance for full skin reconstruction.

As shown in Table 3b, keratin 10 and E-cadherin appeared in $\mathrm{K}$ monoculture model during all the culture periods, but those were not seen in FB monoculture model. On the contrary, type I collagen, synthesized mainly by $\mathrm{FB}$, was not detected in the $\mathrm{K}$ monoculture model. Keratin 10, E-cadherin, and type I collagen were all observed in organotypic $\mathrm{K} \& \mathrm{FB}$ coculture model due to containing two kinds of cells. K normally expressed keratin 10 and E-cadherin, while FB constantly expressed type I collagen. This could roughly prove that the cultured skin cells still kept their phenotype without losing their viability.

\section{2. $\triangle C_{T}$ of $B M$ and ECM proteins}

The relative mRNA expression $\left(\Delta C_{\mathrm{T}}\right)$, the difference in threshold cycles for target gene and house keeping gene, was summarized in Table 4 . The lower $\Delta C_{\mathrm{T}}$ value showed, the earlier the target gene expressed. Tables $4 \mathrm{a}$ and $\mathrm{b}$ are the results of expression of $\mathrm{BM}$ and $\mathrm{ECM}$ proteins, respectively.

At the 1st week (Table 4a), type IV and type VII collagen were expressed both in the $\mathrm{K}$ monoculture and $\mathrm{FB}$ monoculture model, whereas FB monoculture model showed higher expression than those of $\mathrm{K}$ monoculture model. In the FB monoculture model, laminin 5 and integin alpha 6 showed relative low expression level of $\Delta C_{\mathrm{T}}$ value when compared with the rest of the BM proteins.

In the ECM and cytoskeleton gene expression (Table 4b), keratin 10 and E-cadherin were observed in $\mathrm{K}$ monoculture model and $\mathrm{K} \& \mathrm{FB}$ coculture model in all the culture periods. Type I collagen was detected in FB 
Fig. $2 \mathrm{~d}$ was the $-\Delta \Delta C_{\mathrm{T}}$ results of integrin alpha 6 . It showed high expression in $\mathrm{K}$ monoculture model. The FB monoculture model had the lowest expression. All the test groups in integrin alpha 6 expressions were increased at the first 2 weeks and then decreased at the 3rd week.

As the expression of integrin beta 4 (Fig. 2e), there was no expression in the two monoculture models at the 1st week. They all progressively enhanced at the 2 nd week especially the $\mathrm{K}$ monoculture model, and decreased at the 3 rd week. It can be detected in K\&FB coculture model at the 1 st week and sharply increased at the 2 nd week. It was the same scenario as the two monoculture models, which decreased at the 3rd week.

Keratin 10 and E-cadherin were expressed in $\mathrm{K}$ monoculture and $\mathrm{K} \& \mathrm{FB}$ coculture group; those were not expressed in FB monoculture model (Figs. $2 \mathrm{f}$ and g). The relative mRNA expressions of Keratin 10 and E-cadherin significantly increased at the 2 nd week and then gradually receded in the 3rd week. Type I collagen was only expressed in FB monoculture and K\&FB coculture group (Fig. 2h).

\subsection{Gel electrophoresis}

The mRNA expressions of BM proteins and ECM proteins on the three culture models were further checked by gel electrophoresis and the results were summarized in Figs. 3a and b, respectively. Basically, the results from gel electrophoresis were in agreement with those from realtime RT-PCR.

In $\mathrm{BM}$ proteins (Fig. 3a), laminin 5 and integrin beta 4 were absent from $\mathrm{K}$ monoculture model at the first week but appeared at the 2 nd and 3 rd week. The band of integrin beta 4 was not shown in the FB monoculture model at the first week but appeared at the 2nd and 3rd week. Type IV
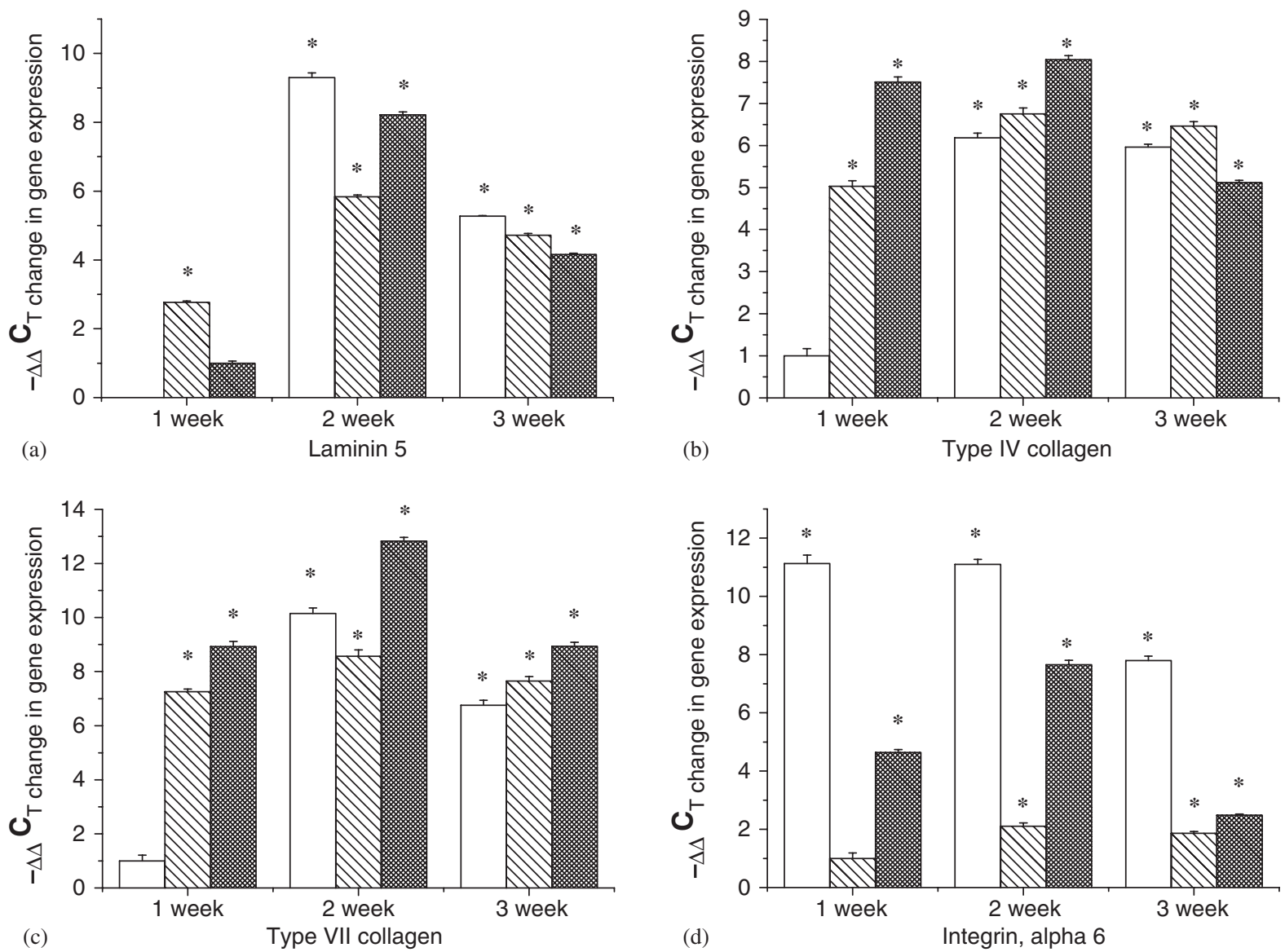

Fig. 2. The comparative $C_{\mathrm{T}}\left(\Delta \Delta C_{\mathrm{T}}\right)$ changes in gene expression of BM and ECM proteins. (a) Laminin 5 was dominantly expressed by keratinocytes throughout the culture time, though it was delayed expression at week 1 . The mRNA gene expression was increased obviously to reach optimal level at week 2 , and then gradually decreased due to reciprocal regulation. (b) and (c) The type IV and type VII collagen were mainly and increasingly observed in FB monoculture at week 1 . The expression of type IV and type VII collagen were increasingly induced during culture time for 2 weeks in organotypic K\&FB coculture model. (d) and (e) The integrin alpha 6 and beta 4 were established and being produced mainly by keratinocytes but modulated by coculture model. The integrin beta 4 was only observed in K\&FB cocultures but not in K or FB monocultures at week 1 . (f) and (g) Keratin 10 and E-cadherin were only expressed in K monoculture and K\&FB coculture group. (h) Type I collagen was only expressed in FB monoculture and K\&FB coculture group. (K: keratinocytes, FB: dermal fibroblasts, K\&FB: keratinocytes and dermal fibroblasts, One-Way ANOVA $n=6 * p<0.05$ : statistically significant.) 

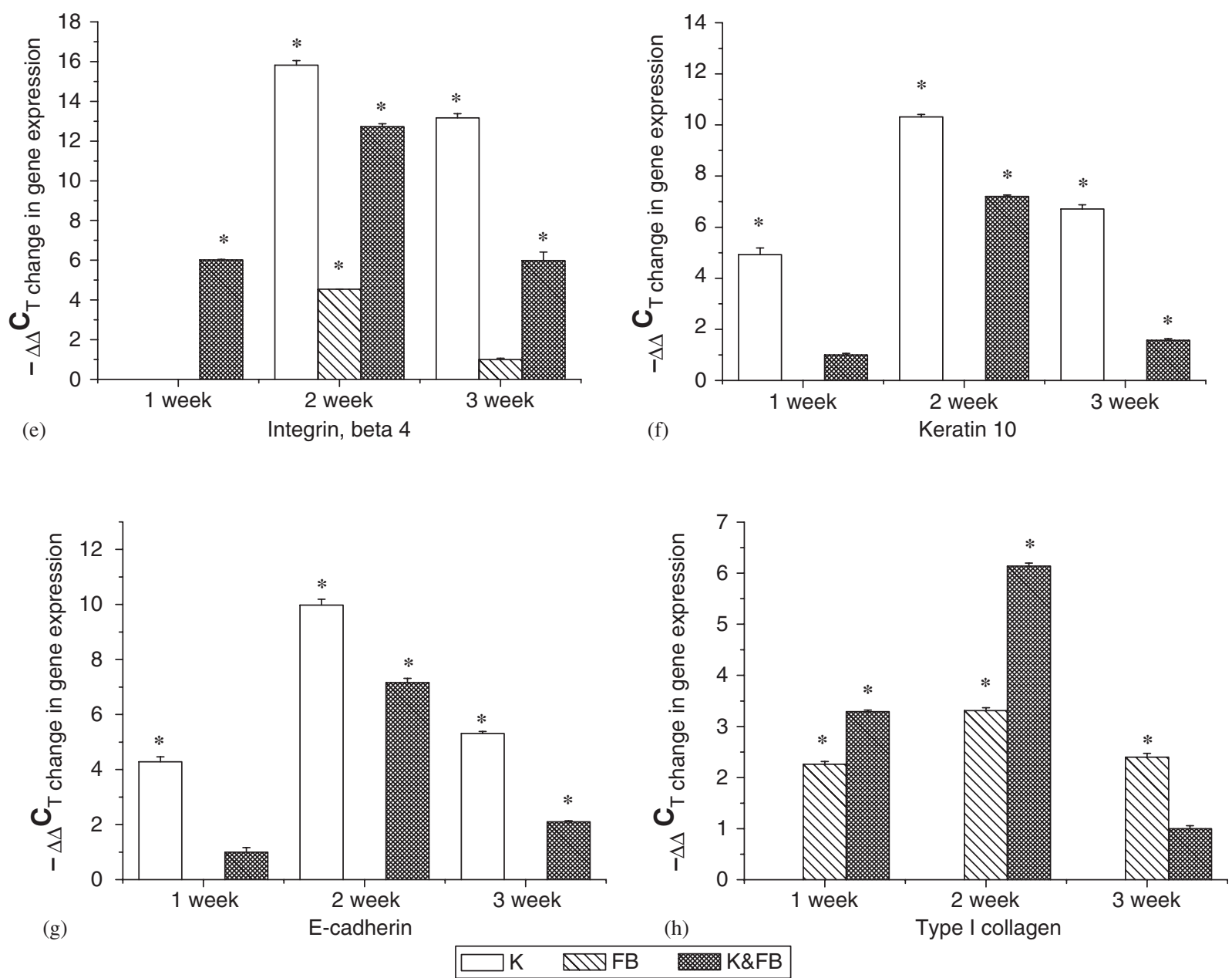

Fig. 2. (Continued)

\begin{tabular}{llllllllll}
\hline K monoculture & \multicolumn{3}{l}{ FB monoculture } & \multicolumn{2}{l}{ K\&FB coculture } \\
\hline $1 w$ & $2 w$ & $3 w$ & $1 w$ & $2 w$ & $3 w$ & $1 w$ & $2 w$ & $3 w$ \\
\hline
\end{tabular}

Laminin 5

Type IV collagen Type VII collagen Integrin, alpha 6 Integrin, beta 4 beta actin

(a)

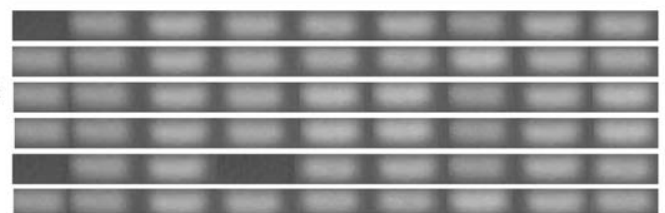

\begin{tabular}{lllllllll} 
K monoculture & \multicolumn{2}{l}{ FB monoculture } & \multicolumn{2}{c}{ K\&FB coculture } \\
\hline $1 w$ & $2 w$ & $3 w$ & $1 w$ & $2 w$ & $3 w$ & $1 w$ & $2 w$ & $3 w$
\end{tabular}

Keratin 10

E-cadherin

Type I collagen

beta actin

(b)

Fig. 3. (a) The result of gel electrophoresis in real time RT-PCR end products (K: keratinocytes, FB: dermal fibroblasts, K\&FB: keratinocytes and dermal fibroblasts), (b) the result of gel electrophoresis in real time RT-PCR end products (K: keratinocytes, FB: dermal fibroblasts, K\&FB: keratinocytes and dermal fibroblasts).

collagen, type VII collagen, and integrin alpha 6 all expressed in $\mathrm{K}$ monoculture model and FB monoculture model in all the culture periods. The BM proteins were expressed in $\mathrm{K} \& \mathrm{FB}$ co-culture model all the way in the 3 weeks.

In ECM and cytoskeleton proteins (Fig. 3b), keratin 10 and $\mathrm{E}$-cadherin were positive in the groups containing $\mathrm{K}$, whereas type I collagen appeared in the groups with FB.

\subsection{Immunohistochemistry stain for the cultured skin equivalents}

The immnohistochemistry stain of organotypic K\&FB coculture model for 3 weeks was shown in Fig. 4. It revealed full skin development with numerous features of epidermal differentiation, which included a well organized basal layer of distinct cylindrical cells, granular layer, and a horny layer.

Laminin 5 was noted at the basal site of $\mathrm{K}$ and represent early marker of cell polarity (Fig. 4a). Type IV collagen and type VII collagen in basal $\mathrm{K}$ traversing the lamina densa was clearly stained by specific monoclonal antibodies (Figs. $4 \mathrm{~b}$ and c). Intrgrin alpha 6 and integrin beta 4 appeared at the basal layer of epidermis; those could be observed only in mature epithelium and were responsible for the anchorage of basal $\mathrm{K}$ to the underlying $\mathrm{BM}$ (Figs. $4 \mathrm{~d}$ and e). The keratin and E-cadherin showed a 

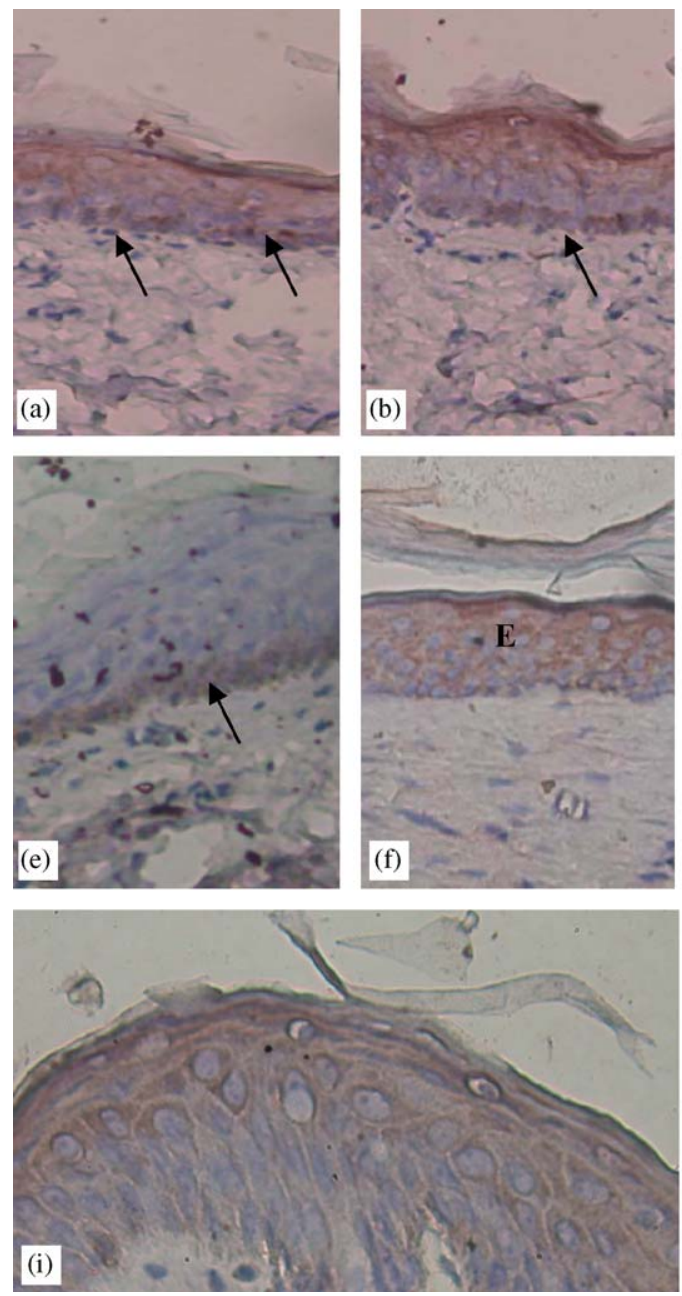
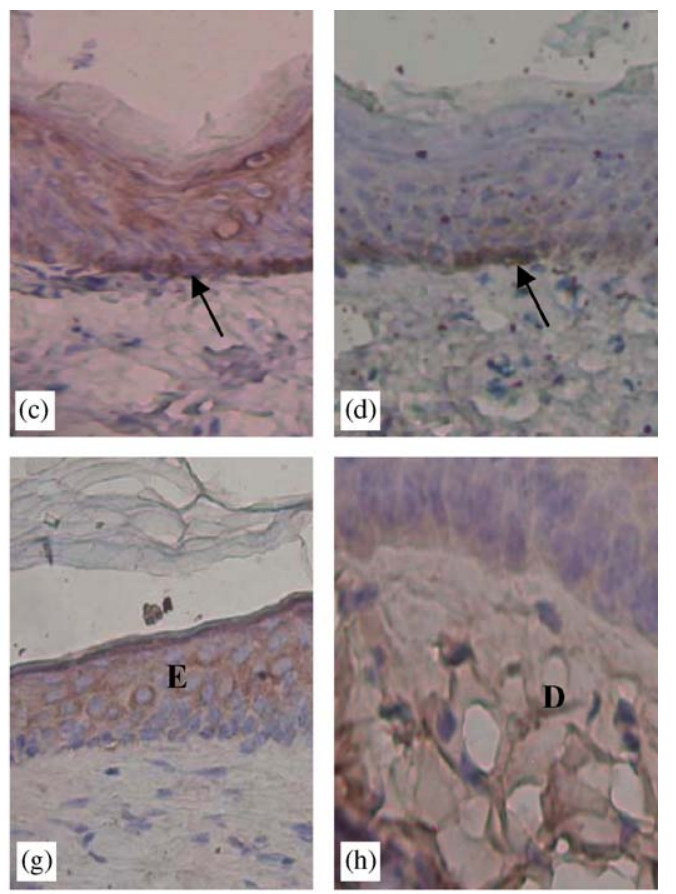

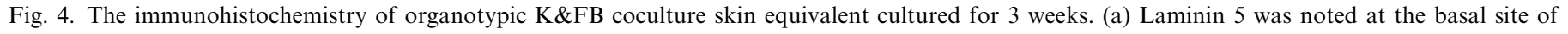

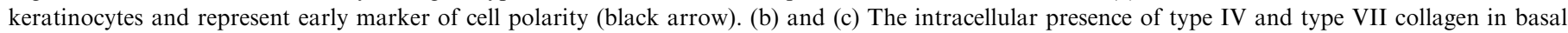

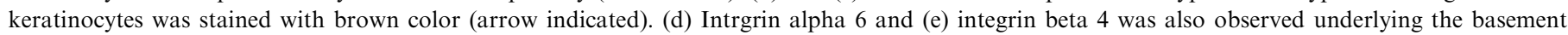

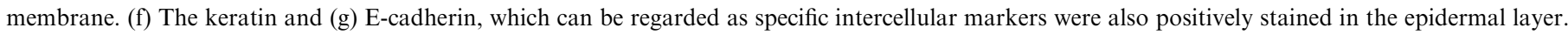

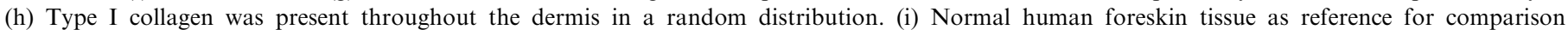
(K: keratinocytes, FB: dermal fibroblasts, K\&FB: keratinocytes and dermal fibroblasts, E: epidermis, D: dermis $(\mathrm{a})-(\mathrm{g})$ : $100 \times$, (h), (i): $200 \times)$.

positive stain in the epidermis layer, which were intercellular markers for normal epidermis (Figs. 4f and g). Type I collagen could be examined throughout the dermis with a form of random distribution (Fig. 4h).

\section{Discussion}

The contribution of $\mathrm{K}$ and $\mathrm{FB}$ to the synthesis of the individual $\mathrm{BM}$ components was difficult to be independently clarified by in vivo studies [22]. The regulatory mechanism of $\mathrm{K}$ and $\mathrm{FB}$ on the synthesis of $\mathrm{BM}$ structure was also hardly to be distinguished due to the complex in vivo conditions [23]. Therefore, we modified and used organotypic $\mathrm{K} \& \mathrm{FB}$ coculture model to mimic the in vivo situation under more defined conditions, and try to elucidate these sophisticated synchronized interactions.

From the results, K\&FB coculture model showed a better expression pattern both in BM and ECM proteins, probably because the two kinds of cells could stimulate each other by released cytokines and growth factors so as to provide better reconstruction environment (Fig. 2). BM and ECM normally expressed and assembled into an order structure (Fig. 4), even when K and FB did not directly contact. This result may provide the evidence that the two kinds of cells go through the paracrine mechanism for communication.

In general, the expression of BM proteins and eventually to form a BM was owing to reciprocal stimulation between $\mathrm{K}$ and $\mathrm{FB}$ [24]. If the culture system only involves one kind of cell, some of BM proteins cannot be normally expressed. For example, integrin beta 4 is not expressed both in $\mathrm{K}$ monoculture model and FB monoculture model until cultured for 2 weeks, but it is expressed in K\&FB coculture model during all the culture time periods (Fig. 2e). This means that K\&FB coculture model containing two kinds of cells for reciprocal stimulation plays an important role in 
Table 5

Summary of the comparative $C_{\mathrm{T}}\left(\Delta \Delta C_{\mathrm{T}}\right)$ changes in gene expression of BM and ECM proteins

\begin{tabular}{|c|c|c|c|c|c|c|c|c|c|}
\hline & \multicolumn{3}{|c|}{$\mathrm{K}$ monoculture } & \multicolumn{3}{|c|}{ FB monoculture } & \multicolumn{3}{|c|}{ Organotype K\&FB coculture } \\
\hline & 1 week & 2 week & 3 week & 1 week & 2 week & 3 week & 1 week & 2 week & 3 week \\
\hline Laminin 5 & - & ++++ & +++ & ++ & +++ & +++ & + & ++++ & +++ \\
\hline Type IV collagen & + & +++ & +++ & +++ & ++++ & ++++ & ++++ & ++++ & +++ \\
\hline Type VII collagen & + & ++++ & +++ & +++ & +++ & +++ & +++ & ++++ & +++ \\
\hline Integrin, alpha 6 & ++++ & ++++ & +++ & + & + & + & ++ & +++ & + \\
\hline Integrin, beta 4 & - & ++++ & +++ & - & ++ & + & ++ & +++ & ++ \\
\hline Keratin 10 & ++ & ++++ & +++ & - & - & - & + & +++ & + \\
\hline E-cadherin & ++ & ++++ & ++ & - & - & - & + & +++ & + \\
\hline Type I collagen & - & - & - & ++ & +++ & ++ & +++ & ++++ & + \\
\hline
\end{tabular}

+ : Slight, ++ : moderate, +++ : abundant, ++++ : very abundant, $-:$ negative.

K: keratinocytes, FB: dermal fibroblasts, K\&FB: keratinocytes and dermal fibroblasts.

establishing the profile of released factors to regulate proliferation/differentiation of $\mathrm{K}$ and results in $\mathrm{BM}$ formation more close to normal skin reconstruction.

The epidermal basement membrane zone is composed of various molecules, each of which plays an important role in dermo-epidermal adhesion. In a skin equivalent model, components of the epidermal BM such as laminin 5, type IV collagen, type VII collagen as well as integrins were detected in the highest level during culture for $1-2$ weeks, and gradually recede thereafter [25,26]. It is probably because in the skin tissue regeneration process, the arrangement and reconstruction of $\mathrm{BM}$ were necessary and started from the beginning when $\mathrm{K}$ and $\mathrm{FB}$ were seeded. The level of these proteins would highly express but should gradually decrease once the BM has been rebuilt. In our results, the BM zone was already well formed and reconstructed at the end of 2 weeks; therefore, the mRNA gene expression of these proteins, which were detected by real time RT-PCR, was all decreased at the 3 weeks compared to that at 2 weeks.

In the previous studies, laminin 5 was one of major components in BM and was secreted mainly by $\mathrm{K}$ in skin tissue $[27,28]$. Although it is not expressed in the 1st week, laiminin 5 reaches the highest level in $\mathrm{K}$ monoculture model in the 2nd week (Fig. 2a), which is so-called gene expression in a time-dependent manner [29]. The expression of ECM and cytoskeleton proteins also has the same phenomenon as BM proteins do. For instance, keratin 10 and E-cadherin are not expressed in FB monoculture model but appear in $\mathrm{K}$ monoculture model (Figs. $2 \mathrm{f}$ and $\mathrm{g}$ ). On the contrary, type I collagen does not appear in the K monoculture model but in FB monoculture model (Fig. 2h). In K\&FB coculture model, all the ECM and cytoskeleton proteins are synthesized (Fig. 3b). In brief, the data presented here indicated that laminin 5, integrin alpha 6, integrin beta 4, keratin 10 and E-cadherin are mainly produced by $\mathrm{K}$, while $\mathrm{FB}$ may contribute for deposition of type IV collagen, type VII collagen, laminin 5 , as well as type I collagen in ECM. We summarized the results in Table 5.
Previous studies have revealed that different culture models could result in different BM proteins expression patterns, such as in de-epidermis or in de-cellularized dermis culture models [30]. Different culture medium may also lead to the different expression results [31]. In our FB monoculture model, FB would secrete BM proteins to help $\mathrm{BM}$ reconstruction that could be due to the exogenous EGF in medium. The phenomenon may not happen if FB are cultured in DMEM without other supplements or growth factors added.

In this study, the results clearly demonstrate the sequential expression, deposition, and structural organization of a cutaneous basement membrane in three different culture models. The dynamics of RNA expression and protein deposition indicate a gradual synthesis pattern and assembly of the different constituents in a complex and tightly regulated epithelial-mesenchymal interplay.

\section{Conclusion}

In this study, sophisticated interplay of regulatory mechanisms between keratinocytes and dermal fibroblasts has been demonstrated. This study provides the evidence of a dynamic keratinocytes and dermal fibroblasts interaction regulating synthesis and assembly of the cutaneous BM and ECM proteins. Organotypic K\&FB coculture model to mimic real skin situation provides an attractive model to elucidate the role that different cell types play in the regulation of epidermal morphogenesis and BM formation. With this coculture model, we are able to mimic the in vivo situation under more defined conditions to study in detail about time-dependent expression of BM and ECM constituents.

\section{References}

[1] Inoue S. Ultrastructure of basement membranes. Int Rev Cytol 1989;117:57-98.

[2] Amano S, Akutsu N, Matsunaga Y, Nishiyama T, Champliaud MF, Burgeson RE, et al. Importance of balance between extracellular 
matrix synthesis and degradation in basement membrane formation. Exp Cell Res 2001;271(2):249-62.

[3] Burgeson RE, Christiano AM. The dermal-epidermal junction. Curr Opin Cell Biol 1997;9(5):651-8.

[4] Marinkovich MP, Keene DR, Rimberg CS, Burgeson RE. Cellular origin of the dermal-epidermal basement membrane. Dev Dyn 1993; 197(4):255-67.

[5] Christiano AM, Uitto J. Molecular complexity of the cutaneous basement membrane zone. Revelations from the paradigms of epidermolysis bullosa. Exp Dermatol 1996;5:1-11.

[6] Aberdam DF, Galliano J, Vailly J, Pulkkinen L, Bonifas J, Christiano AM, et al. Herlitz's junctional epidermolysis bullosa is linked to mutations in the gene (LAMC2) for gamma 2 subunit of nicein:kalinin (LAMININ-5). Nat Genet 1994;6:299-304.

[7] Chan LS, Lapiere JC, Chen M, Traczyk T, Mancini AJ, Paller AS, et al. Bullous systemic lupus erythematosus with autoantibodies recognizing multiple skin basement membrane components, bullous pemphigoid antigen 1, laminin-5, laminin-6, and type VII collagen. Arch Dermatol 1999;135(5):569-73.

[8] Huber M, Scaletta C, Benathan M, Frenk E, Greenhalgh DA, Rothnagel JA, et al. Abnormal keratin 1 and 10 cytoskeleton in cultured keratinocytes from epidermolytic hyperkeratosis caused by keratin 10 mutations. J Invest Dermatol 1994;102(5):691-4.

[9] Chu PG, Weiss LM. Keratin expression in human tissues and neoplasms. Histopathology 2002;40(5):403-39.

[10] Amagai M, Klaus-Kovtun V, Stanley JR. Autoantibodies against a novel epithelial cadherin in pemphigus vulgaris, a disease of cell adhesion. Cell 1991;67(5):869-77.

[11] Young P, Boussadia O, Halfter H, Grose R, Berger P, Leone DP, et al. E-cadherin controls adherens junctions in the epidermis and the renewal of hair follicles. EMBO J 2003;22(21):5723-33.

[12] Spirito F, Chavanas S, Prost-Squarcioni C, Pulkkinen L, Fraitag S, Bodemer C, et al. Reduced expression of the epithelial adhesion ligand laminin 5 in the skin causes intradermal tissue separation. $\mathbf{J}$ Biol Chem 2001;276(22):18828-35.

[13] Funderburgh JL, Mann MM, Funderburgh ML. Keratocyte phenotype mediates proteoglycan structure: a role for fibroblasts in corneal fibrosis. J Biol Chem 2003;278(46):45629-37.

[14] Nievers MG, Schaapveld RQ, Sonnenberg A. Biology and function of hemidesmosomes. Matrix Biol 1999;18(1):5-17.

[15] El Ghalbzouri A, Jonkman MF, Dijkman R, Ponec M. Basement membrane reconstruction in human skin equivalents is regulated by fibroblasts and/or exogenously activated keratinocytes. J Invest Dermatol 2005;124(1):79-86.

[16] Smola H, Stark HJ, Thiekotter G, Mirancea N, Krieg T, Fusenig NE. Dynamics of basement membrane formation by keratinocytefibroblast interactions in organotypic skin culture. Exp Cell Res 1998;239(2):399-410.

[17] Wang TW, Wu HC, Huang YC, Sun JS, Lin FH. Biomimetic bilayered gelatin-chondroitin 6 sulfate-hyaluronic acid biopolymer as the scaffold for skin equivalent tissue engineering. Artif Organs 2006;30(3):141-9.

[18] Huang YC, Wang TW, Sun JS, Lin FH. Epidermal morphogenesis in an in-vitro model using a fibroblasts-embedded collagen scaffold. J Biomed Sci 2005;12(6):855-67.

[19] Kang HW, Tabata Y, Ikada Y. Fabrication of porous gelatin scaffolds for tissue engineering. Biomaterials 1999;20(14):1339-44.

[20] Choi YS, Hong SR, Lee YM, Song KW, Park MH, Nam YS. Studies on gelatin-containing artificial skin: II. Preparation and characterization of cross-linked gelatin-hyaluronate sponge. J Biomed Mater Res 1999;48(5):631-9.

[21] Lee SB, Jeon HW, Lee YW, Lee YM, Song KW, Park MH, et al. Bioartificial skin composed of gelatin and $(1 \rightarrow 3),(1 \rightarrow 6)$-beta-glucan. Biomaterials 2003;24(14):2503-11.

[22] Bell E, Ehrlich HP, Buttle DJ, Nakatsuji T. Living tissue formed in vitro and accepted as skin-equivalent tissue of full thickness. Science 1981;211(4486):1052-4.

[23] Boyce ST, Christianson DJ, Hansbrough JF. Structure of a collagenGAG dermal skin substitute optimized for cultured human epidermal keratinocytes. J Biomed Mater Res 1988;22(10):939-57.

[24] Konig A, Bruckner-Tuderman L. Epithelial-mesenchymal interactions enhance expression of collagen VII in vitro. J Invest Dermatol 1991;96(6):803-8.

[25] Ralston DR, Layton C, Dalley AJ, Boyce SG, Freedlander E, Mac Neil S. The requirement for basement membrane antigens in the production of human epidermal/dermal composites in vitro. Br $\mathbf{J}$ Dermatol 1999;140(4):605-15.

[26] Amano S, Akutsu N, Matsunaga Y, Nishiyama T, Champliaud MF, Burgeson RE, et al. Importance of balance between extracellular matrix synthesis and degradation in basement membrane formation. Exp Cell Res 2001;271(2):249-62.

[27] Tsunenaga M, Adachi E, Amano S, Burgeson RE, Nishiyama T. Laminin 5 can promote assembly of the lamina densa in the skin equivalent model. Matrix Biol 1998;17(8-9):603-13.

[28] Nishiyama T, Amano S, Tsunenaga M, Kadoya K, Takeda A, Adachi E, et al. The importance of laminin 5 in the dermal-epidermal basement membrane. J Dermatol Sci 2000;24(Suppl 1):S51-9.

[29] Fusenig NE, Leigh I, Lane B, Watt F. Epithelial-mesenchymal interactions regulate keratinocyte growth and differentiation in vitro. In: The keratinocyte handbook. Cambridge, UK: Cambridge University Press; 1994. p. 71-97.

[30] Fleischmajer R, Utani A, MacDonald ED, Perlish JS, Pan TC, $\mathrm{Chu} \mathrm{ML}$, et al. Initiation of skin basement membrane formation at the epidermo-dermal interface involves assembly of laminins through binding to cell membrane receptors. J Cell Sci 1998;111(14): 1929-40.

[31] Eckhart L, Reinisch C, Inoue S, Messner P, Dockal M, Mayer C, et al. A basement membrane-like matrix formed by cell-released proteins at the medium/air interface supports growth of keratinocytes. Eur J Cell Biol 2003;82(11):549-55. 